\title{
Association between bicortical screw fixation at upper instrumented vertebra and risk for upper instrumented vertebra fracture
}

\author{
Young-Seop Park, MD, ${ }^{1}$ Seung-Jae Hyun, MD, PhD, ${ }^{2}$ Ho Yong Choi, MD, ${ }^{2}$ Ki-Jeong Kim, MD, PhD, ${ }^{2}$ \\ and Tae-Ahn Jahng, MD, PhD²
}

\begin{abstract}
1Department of Neurosurgery, Gyeongsang National University Changwon Hospital, Gyeongsang National University Graduate School of Medicine, Jinju; and 'Department of Neurosurgery, Spine Center, Seoul National University Bundang Hospital, Seoul National University College of Medicine, Seongnam, Gyeonggi, Korea
\end{abstract}

\begin{abstract}
OBJECTIVE The aim of this study was to investigate the risk of upper instrumented vertebra (UIV) fractures associated with UIV screw fixation (unicortical vs bicortical) and polymethylmethacrylate (PMMA) augmentation after adult spinal deformity surgery.

METHODS A single-center, single-surgeon consecutive series of adult patients who underwent lumbar fusion for $\geq 4$ levels (that is, the lower instrumented vertebra at the sacrum or pelvis and the UIV of the thoracolumbar spine [T9-L2]) were retrospectively reviewed. Age, sex, follow-up duration, sagittal UIV angle immediately postoperatively including several balance-related parameters (lumbar lordosis [LL], pelvic incidence, and sagittal vertical axis), bone mineral density, UIV screw fixation type, UIV PMMA augmentation, and UIV fracture were evaluated. Patients were divided into 3 groups: Group U, 15 patients with unicortical screw fixation at the UIV; Group P, 16 with bicortical screw fixation and PMMA augmentation at the UIV; and Group B, 21 with bicortical screw fixation without PMMA augmentation at the UIV.
\end{abstract}

RESULTS The mean number of levels fused was $6.5 \pm 2.5,7.5 \pm 2.5$, and $6.5 \pm 2.5$; the median age was $50 \pm 29,72 \pm$ 6 , and $59 \pm 24$ years; and the mean follow-up was $31.5 \pm 23.5,13 \pm 6$, and $24 \pm 17.5$ months in Groups U, P, and B, respectively $(p>0.05)$. There were no significant differences in balance-related parameters (LL, sagittal vertical axis, pelvic incidence-LL, and so on) among the groups. UIV fracture rates in Groups U (0\%), P (31.3\%), and B (42.9\%) increased in sequence by group $(p=0.006)$. UIV bicortical screw fixation increased the risk for UIV fracture (OR $5.39 ; p=0.02)$.

CONCLUSIONS Bicortical screw fixation at the UIV is a major risk factor for early UIV compression fracture, regardless of whether a thoracolumbosacral orthosis is used. To reduce the proximal junctional failure, unicortical screw fixation at the UIV is essential in adult spinal deformity correction surgery.

https://thejns.org/doi/abs/10.3171/2016.10.SPINE16535

KEY WORDS acute proximal junctional failure; upper instrumented vertebra; bicortical screw fixation; UIV compression fracture; UIV screw fixation; surgical technique

$\mathrm{P}$ OSTERIOR lumbar long instrumented fusion has been described for various conditions, including degenerative flat-back syndrome, degenerative lumbar scoliosis, metastatic spinal tumor, degenerative spondylolisthesis, and in revision cases of pseudarthroses. ${ }^{5,8,9,11,12,14,15,18,25}$ Regardless of modern surgical technology, proximal junctional failures (PJFs) are still a major concern, especially after adult deformity surgery. PJF is a widely recognized complication of spinal deformity surgery. It is obvious that degeneration of the proximal junction of the fused vertebra accelerates because of increased stress. Such failures include screw pullout in the upper instrumented vertebra (UIV), UIV compression fracture, adjacent vertebral compression fractures, adjacent-disc herniation, and adjacentsegment degeneration. These kinds of PJF usually cause kyphosis and, in some cases, resulting paraplegia. These

ABBREVIATIONS APJF = acute proximal junctional failure; BMD = bone mineral density; LIV = lower instrumented vertebra; LL = lumbar lordosis; ODI = Oswestry Disability Index; PI = pelvic incidence; PJF = proximal junctional failure; PJK = proximal junctional kyphosis; PMMA = polymethylmethacrylate; SVA = sagittal vertical axis; UIV = upper instrumented vertebra.

SUBMITTED May 8, 2016. ACCEPTED October 11, 2016.

INCLUDE WHEN CITING Published online March 3, 2017; DOI: 10.3171/2016.10.SPINE16535. 
conditions require decompression with proximal extension of the instrumentation, sometimes to the upper thoracic spine.

Many theories have been used to explain these types of PJF. Known risk factors include older age, osteoporosis, female sex, high UIV angle, preoperative kyphosis adjacent to the UIV, inadequate implant systems, the level of the UIV, preoperative hyperkyphotic thoracic alignment, sagittal imbalance, and acute correction of sagittal imbalance. ${ }^{4,12,16,19-22,26}$ However, among these factors, it is not clear which can explain the early UIV fracture that occurs in patients (even in those who wear a brace) who have undergone a successful surgery (Fig. 1).

From the biomechanical perspective, spine surgeons are familiar with bicortical screw fixation, especially in osteoporotic adult deformity surgery. UIV fracture can occur even when patients are wearing a brace. Therefore, we considered and evaluated the possibility that UIV bicortical screw fixation may be a risk factor for early UIV fracture.

\section{Methods}

Following approval from the research ethics board, this retrospective review was performed in consecutive patients (age at surgery $>18$ years) who underwent long-segment lumbar fusion between January 2011 and January 2015. All surgeries were performed by a single surgeon (S.J.H.) at a single institution. All constructs comprised pedicle screws from the same company. Local autologous bone grafts with allogeneic bone chip and demineralized bone matrix were used for fusion. All patients wore a thoracolumbosacral orthosis brace for 90 days after the index surgery.

Patients who had a minimum of 4 levels fused (that is, the lower instrumented vertebra [LIV] at the sacrum or pelvis and the UIV from T-9 to L-2) were retrospectively reviewed. Patients excluded from the study included those lost to follow-up (4 patients) and those with upper thoracic instrumentation (17 patients). Fifty-two patients met the inclusion criteria. For all patients, the UIV screw type (bicortical vs unicortical) was confirmed by postoperative CT scanning. No patients had undergone thoracic procedures and surgery proximal to the UIV. The mean follow-up was calculated based on the date of the final follow-up radiograph or until the patient underwent revision surgery.

Clinical and radiographic data were collected by a clinical fellow and reviewed by a professor. The pelvic incidence (PI), sagittal UIV angle immediately postoperatively, lumbar lordosis (LL; pre- and postoperation), sagittal vertical axis (SVA; pre- and postoperation), and UIV polymethylmethacrylate (PMMA) augmentation were checked on standing whole-spine lateral radiograph; UIV screw type was evaluated on immediate postoperative spinal CT scan. Bone mineral density (BMD), follow-up duration, and demographic data, including age and sex, were also recorded.

To determine whether there was a correlation among the screw type, PMMA augmentation, and UIV fracture, patients were divided into 3 groups. Group U consisted of 15 patients who underwent unicortical screw fixation

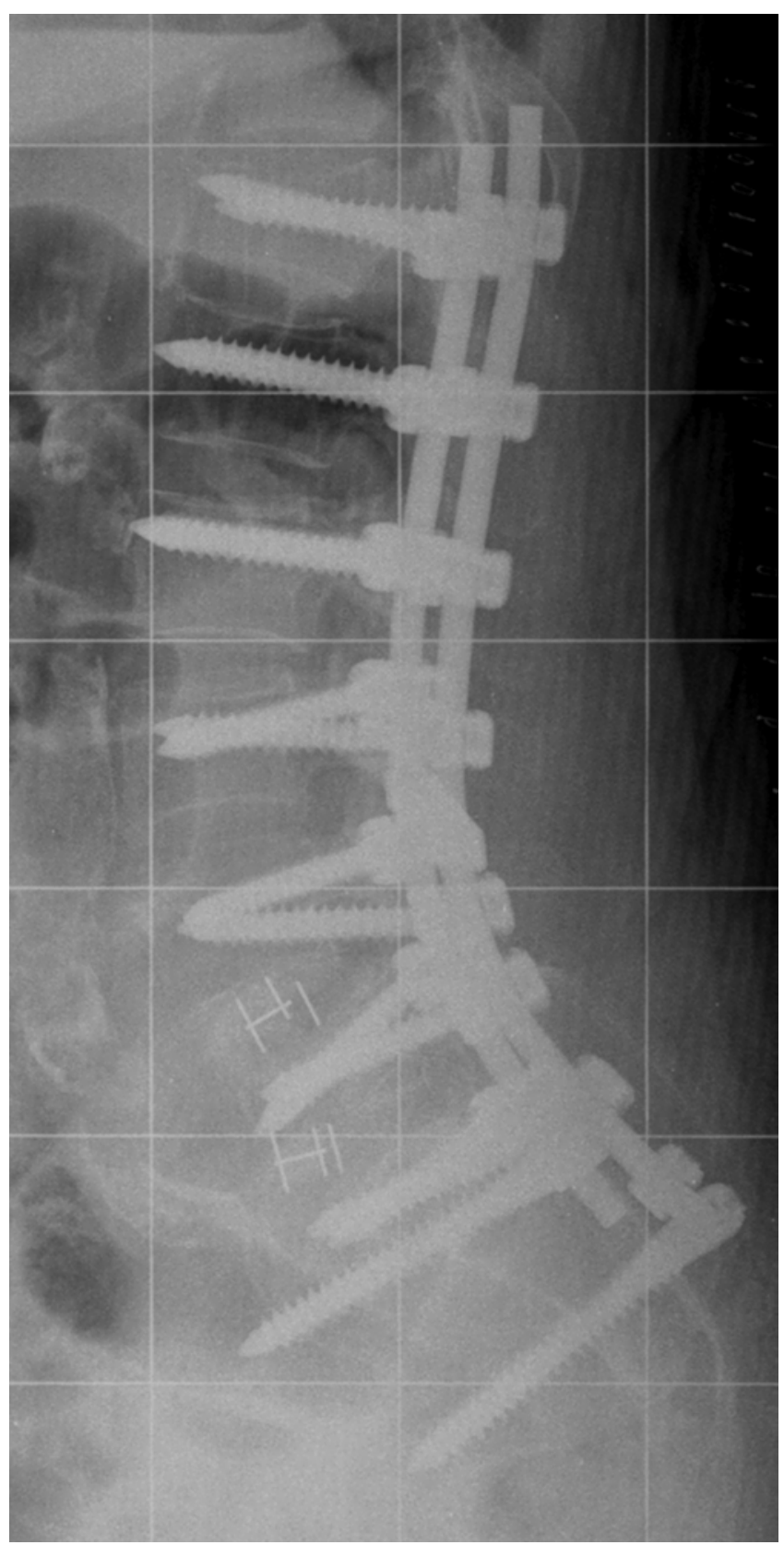

FIG. 1. Five-day postoperative standing radiograph demonstrating an early UIV fracture.

at the UIV. Group P consisted of 16 patients who underwent bicortical screw fixation with PMMA augmentation at the UIV. Group B consisted of 21 patients who underwent bicortical screw fixation at the UIV without PMMA augmentation (Fig. 2).

\section{Statistical Analysis}

By analyzing the serial follow-up radiographs, we investigated the occurrence and time to UIV fracture. To perform statistical analysis, we used SPSS, version 19.0 (SPSS, Inc.). A p value $<0.05$ was considered statistically significant. The $\mathrm{p}$ values for age, follow-up duration, num- 


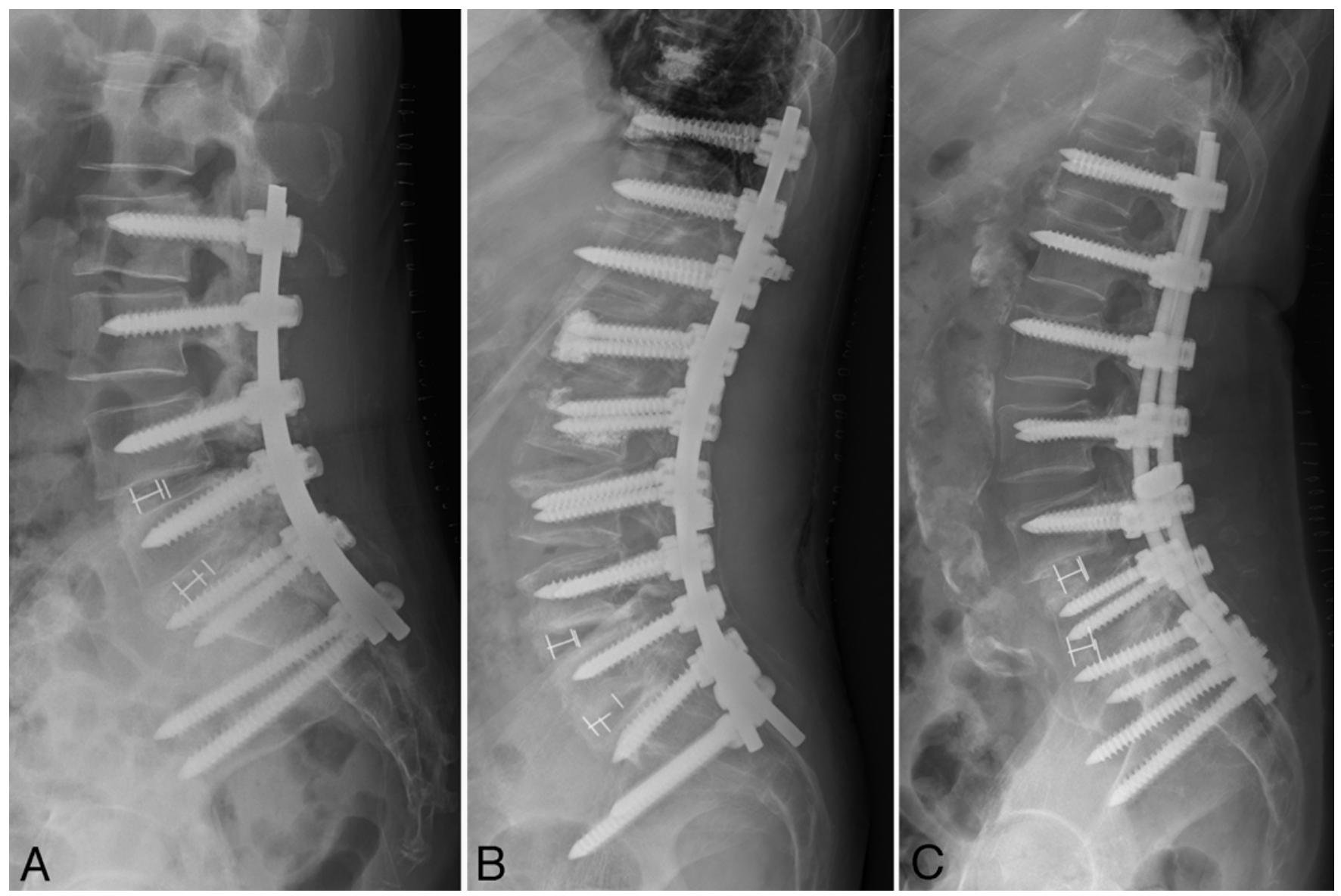

FIG. 2. Postoperative radiographs obtained in a patient from each of the 3 groups. A: UIV unicortical screw fixation (Group U). B: UIV bicortical screw fixation with PMMA augmentation (Group P). C: UIV bicortical screw fixation without PMMA augmentation (Group B).

ber of fused segments, BMD, UIV angle, and sex were calculated using 1-way ANOVA for normally distributed clinical characteristics. Linear-by-linear association analysis was used to analyze differences in sex proportions, 1-way ANOVA was used to analyze differences in BMD and the UIV angle, and the Kruskal-Wallis test was used for all other variables. Outcomes were analyzed using Fisher's exact test for the pairwise comparisons between groups ( $\mathrm{U}$ and $\mathrm{P}, \mathrm{P}$ and $\mathrm{B}$, and $\mathrm{B}$ and $\mathrm{U}$ ); a p value of 0.017 was considered statistically significant (accounting for Bonferroni correction). Linear-by-linear association analysis was also performed to compare the rates of fracture among the 3 groups.

\section{Results}

\section{Comparison of Demographic Data Among the Groups}

There were 3 men and 12 women in Group U, 16 women in Group P, and 2 men and 19 women in Group $\mathrm{B}$ (Table 1). The median age of the enrolled patients was 52 years (range $21-83$ years), with female predominance (89\%). The mean follow-up was 1.6 years (range 0.6-4.6 years). There were no significant differences in age at the time of surgery $(50,72$, and 59 years in Groups U, P, and $\mathrm{B}$, respectively), number of levels fused $(6.5,7.5$, and 6.5 in
Groups U, P, and B, respectively), and BMD (-1.01, -2.17 , and $-1.83 \mathrm{~kg} / \mathrm{m}^{2}$ in Groups U, P, and B, respectively).

The majority of patients underwent surgery for degenerative kyphosis, scoliosis, or both. The next most common cause of surgery was adjacent-segment disease. Most patients' LIV included the pelvis (100\% in Groups U and P, $85.7 \%$ in Group B). The mean follow-up was 31.5 months for Group U, 13 months for Group P, and 24 months for Group B.

\section{Radiological Comparison of the Groups}

\section{LL, LL Change, PI, and PI-LL}

Group $\mathrm{U}$ demonstrated an average preoperative LL angle of $-24.1^{\circ}$ and a postoperative LL angle of $-49.5^{\circ}$. The immediate postoperative LL angle increase (preoperative to 2 weeks postoperative) was $24.7^{\circ}$. Group P demonstrated an average preoperative LL angle of $-13.5^{\circ}$ and a postoperative $\mathrm{LL}$ angle of $-47.9^{\circ}$. The immediate postoperative LL angle increase (preoperative to 2 weeks postoperative) was $34.1^{\circ}$. Group B demonstrated an average preoperative LL angle of $-16.0^{\circ}$ and a postoperative LL angle of $-52.6^{\circ}$. The immediate postoperative LL angle increase (preoperative to 2 weeks postoperative) was $35.1^{\circ}$. There was no significantly different change in the LL angle among the 3 groups between the measurements made 
TABLE 1. Comparison of clinical data among groups

\begin{tabular}{|c|c|c|c|c|}
\hline Variable & $\begin{array}{c}\text { Group U: Unicortical } \\
\text { UIV Screw }\end{array}$ & $\begin{array}{c}\text { Group P: Bicortical UIV } \\
\text { Screw + PMMA }\end{array}$ & $\begin{array}{c}\text { Group B: Bicortical } \\
\text { UIV Screw }\end{array}$ & $\mathrm{p}$ Value \\
\hline No. of patients & 15 & 16 & 21 & \\
\hline Sex & & & & 0.373 \\
\hline Male & 3 & 0 & 2 & \\
\hline Female & 12 & 16 & 19 & \\
\hline Median age in yrs (range) & $50(21-79)$ & $72(66-78)$ & $59(35-83)$ & 0.147 \\
\hline Mean no. of levels fused (range) & $6.5(4-9)$ & $7.5(5-10)$ & $6.5(4-9)$ & 0.168 \\
\hline Mean length of follow-up in mos (range) & $31.5(8-55)$ & $13(7-19)$ & $24(7-42)$ & 0.066 \\
\hline Mean BMD (range) & $-1.01(-4.4$ to 1.8$)$ & $-2.17(-3.7$ to -0.3$)$ & $-1.83(-4.9$ to 2.2$)$ & 0.106 \\
\hline Mean UIV angle, ${ }^{\circ}$ (range) & $-6.13(-17$ to 6$)$ & $-6.94(-18$ to 9$)$ & $-7.64(-21$ to 10$)$ & 0.828 \\
\hline \multicolumn{5}{|l|}{ Diagnosis } \\
\hline Degenerative deformity & 10 & 9 & 12 & \\
\hline Posttraumatic kyphosis & 1 & 0 & 2 & \\
\hline Congenital deformity & 1 & 0 & 2 & \\
\hline latrogenic, PJK & 3 & 7 & 4 & \\
\hline Tuberculosis kyphosis & 0 & 0 & 1 & \\
\hline \multicolumn{5}{|l|}{ UIV } \\
\hline $\mathrm{T}-9$ & 1 & 5 & 4 & \\
\hline $\mathrm{T}-10$ & 2 & 5 & 2 & \\
\hline $\mathrm{T}-11$ & 1 & 1 & 3 & \\
\hline $\mathrm{T}-12$ & 4 & 1 & 6 & \\
\hline $\mathrm{L}-1$ & 4 & 4 & 3 & \\
\hline $\mathrm{L}-2$ & 3 & 0 & 3 & \\
\hline \multicolumn{5}{|l|}{ LIV } \\
\hline S-1 & 15 & 16 & 18 & \\
\hline Pelvis & 0 & 0 & 3 & \\
\hline Revision following index surgery & 0 & 2 & 2 & \\
\hline
\end{tabular}

preoperatively and 2 weeks postoperatively $(\mathrm{p}=0.335)$. There was also no significant difference between the PI and PI-LL values (Table 2).

\section{SVA Change}

Group U demonstrated a preoperative SVA of $10.57 \mathrm{~cm}$ and a 2 -week postoperative SVA of $1.48 \mathrm{~cm}$. The immediate postoperative SVA change (preoperative to 2 weeks postoperation) was $-9.4 \mathrm{~cm}$. Group $\mathrm{P}$ demonstrated a preoperative SVA of $14.29 \mathrm{~cm}$ and a 2-week postoperative SVA of $2.06 \mathrm{~cm}$. The immediate postoperative SVA change (preoperative to 2 weeks postoperation) was -11.5

TABLE 2. Comparison of radiological data among groups

\begin{tabular}{lcccc}
\hline \multicolumn{1}{c}{ Variable } & Group U & Group P & Group B & p Value \\
\hline No. of patients & 15 & 16 & 21 & \\
\hline SVA in cm, C-7 plumb to S-1 & & & & \\
\hline Preop & $10.57 \pm 8.1$ & $14.29 \pm 7.7$ & $12.36 \pm 6.7$ & 0.501 \\
\hline 2 wks postop & $1.48 \pm 4.4$ & $2.06 \pm 4.2$ & $-1.26 \pm 3.2$ & 0.833 \\
\hline Preop to 2 wks postop & $-9.4 \pm 4.8$ & $-11.5 \pm 6.2$ & $-10.8 \pm 7.2$ & 0.584 \\
\hline LL angle $\left(^{\circ}\right)$, T12-S1 & & & $-16.0 \pm 21.2$ & 0.227 \\
\hline Preop & $-24.1 \pm 20.5$ & $-13.5 \pm 22.5$ & $-52.6 \pm 15.7$ & 0.483 \\
\hline 2 wks postop & $-49.5 \pm 18.4$ & $-47.9 \pm 13.4$ & $-35.1 \pm 20.3$ & 0.335 \\
\hline 2 wks postop to preop & $-24.7 \pm 16.9$ & $-34.1 \pm 17.2$ & $58.4 \pm 26.4$ & 0.998 \\
\hline PI angle $\left(^{\circ}\right)$ & $57.9 \pm 30.2$ & $58.0 \pm 17.8$ & $5.8 \pm 19.3$ & 0.498 \\
\hline PI-LL angle $\left(^{\circ}\right)$, 2 wks postop & $8.4 \pm 12.8$ & $10.1 \pm 17.3$ & $-7.64 \pm 14.2$ & 0.837 \\
\hline UIV angle $\left(^{\circ}\right)$ & $-6.13 \pm 11.2$ & $-6.94 \pm 12.3$ & & \\
\hline
\end{tabular}


TABLE 3. Comparison of fracture-related factors between UIV fracture and UIV nonfracture groups

\begin{tabular}{lccc}
\hline \multicolumn{1}{c}{ Factor } & $\begin{array}{c}\text { UIV Fracture } \\
\text { Group }\end{array}$ & $\begin{array}{c}\text { UIV Nonfracture } \\
\text { Group }\end{array}$ & p Value \\
\hline No. of patients & 14 & 38 & \\
\hline Age in yrs & $71.29^{*}$ & $66.13^{*}$ & 0.111 \\
\hline UIV angle $\left(^{\circ}\right)$ & $-7.93^{*}$ & $-6.64^{*}$ & 0.568 \\
\hline BMD & $-2.05^{*}$ & $-1.57^{*}$ & 0.549 \\
\hline Female (\%) & $13(92.86)$ & $34(89.47)$ & 1.00 \\
\hline $\begin{array}{l}\text { No. of patients w/ PMMA } \\
\text { augmentation }(\%)\end{array}$ & $5(35.71)$ & $12(31.58)$ & 1.00 \\
\hline No. of fused segments & $6.57^{*}$ & $6.71^{*}$ & 0.768 \\
\hline Follow-up in mos & $18.95^{*}$ & $19.14^{*}$ & 0.944 \\
\hline * Mean values & & &
\end{tabular}

* Mean values.

$\mathrm{cm}$. Group B demonstrated a preoperative SVA of 12.36 $\mathrm{cm}$ and a 2-week postoperative SVA of $1.26 \mathrm{~cm}$. The immediate postoperative SVA change (preoperative to 2 weeks postoperation) was $-10.8 \mathrm{~cm}$. There were no significant differences in SVA change among the groups between preoperation and 2 weeks postoperation $(\mathrm{p}=0.584)$.

\section{Immediate Postoperative UIV Angle}

There were no significant differences in UIV angle $\left(-6.13^{\circ},-6.94^{\circ}\right.$, and $-7.64^{\circ}$ in Groups $\mathrm{U}, \mathrm{P}$, and $\mathrm{B}$, respectively; $p>0.05$ ) among the groups.

\section{Effect of UIV Screw on UIV Compression Fractures}

UIV bicortical screw fixation was highly correlated with developing a fracture of the UIV. The average fracture rate was $0 \%$ in Group U, 31.3\% in Group P, and $42.9 \%$ in Group B. In linear-by-linear association analysis, the UIV fracture rate increased in sequence by group (Group U 0\%, Group P 31.3\%, and Group B 42.9\%; p = 0.006). This difference was significant between Groups A and B $(\mathrm{p}=0.005)$. However, differences between Groups $\mathrm{P}$ and $\mathrm{B}(\mathrm{p}=0.471)$ and Groups $\mathrm{U}$ and $\mathrm{P}(\mathrm{p}=0.043)$ were not statistically significant. There were no statistically significantly different factors between the UIV fracture group and the non-UIV fracture group (Table 3). There were no cases of surgical site infection or death.

\section{Clinical Outcomes}

No patients in Group U had a UIV fracture. Group P had 5 patients (31.3\%) and Group B had 9 patients (42.9\%) with a UIV fracture. The mean time to UIV fracture was 53 days in Group P and 27.3 days in Group B. None of the 15 patients in Group $U$ had any fractures of the vertebra proximal to the UIV. The mean interval between the index surgery and revision surgery was 90 days in Group $\mathrm{P}$ and 170 days in Group B. The 3 groups were similar with regard to the mean preoperative Oswestry Disability Index (ODI) score $(31,30$, and 33 for Groups U, P, and B, respectively) and postoperative ODI score $(16.8,19.6$, and 20.5 for Groups U, P, and B, respectively). There was a positive correlation between the preoperative and postoperative ODI score (Pearson correlation coefficient 0.82; $\mathrm{p}$
$=0.005)$. The difference among the groups between the preoperative and postoperative ODI score was not significant. The ODI score did not significantly correlate with sex, age, BMD, or the number of levels fused.

\section{Discussion}

Stress concentration on the proximal junction after posterior long instrumented fusion, from the thoracolumbar spine to S-1 or the pelvis, has demonstrated several junctional changes: PJFs, proximal junctional kyphosis (PJK), junctional disc rupture, and junctional spinal stenosis. ${ }^{13}$ The prevalence of PJK following posterior long instrumented fusion for adult spinal deformity has been shown to be high but clinically insignificant, ${ }^{3,8,9}$ Although efforts have been made to reduce PJF, there is no consensus on how to do so. In a study by Kim et al., there was no difference in prevalence of PJK between the proximal thoracic and distal thoracic groups, and they showed similar outcomes. ${ }^{10}$ A multicenter study performed by Hostin et al. identified 68 cases of acute PJF (APJF) among 1218 consecutive surgeries (5.6\%). ${ }^{7}$ The authors concluded that the mode of failure differed depending on the location of the UIV, with thoracolumbar failures more likely due to fracture and upper thoracic failures more likely due to soft-tissue failure. Many authors seem to agree that the most common mode of failure in lower thoracic or lumbar fusions is a UIV fracture., ${ }^{1,10,23,24}$

Some have argued that APJF was more common in patients with preoperative sagittal imbalance..$^{23}$ However, Smith et al. concluded that sagittal balance correction was not correlated with change in the incidence of early PJF. ${ }^{24}$ Lewis et al. reported that a high UIV sagittal angle shown on intraoperative lateral radiographs is strongly associated with UIV fractures. ${ }^{17}$ However, in our study, there were no meaningful differences between the UIV sagittal angle and UIV fracture. Previous researchers have reported that UIVs of L-1 or L-2 had a higher rate of adjacent-segment or UIV failure. ${ }^{17,27}$

Another investigator reported that the UIV fracture rate was higher when the UIV was at T-10. ${ }^{1}$ Yet, Kim and colleagues reported that proximal fusion levels (T-9, T-11, and L-1) did not demonstrate significant radiographic and clinical outcomes or revision prevalence postoperatively. ${ }^{14}$ A PJK $>15^{\circ}$ without fracture or hardware failure had the longest revision-free survival. ${ }^{1}$ Postoperative proximal junctional angle $>5^{\circ}$ and a greater correction of LL were independent risk factors for APJF. ${ }^{1}$ Junctional problems after deformity corrective surgery require further extensive research to minimize their incidence, especially in the aging population. ${ }^{2}$

In the current study, we were limited by our research on APJF, especially UIV compression fracture. In addition, we only evaluated UIV from T-9 to L-2 and LIV to S-1 or pelvis to perform a well-controlled study and create an environment in which a fracture could have occurred. It is well known that the thoracolumbar junction is easy to fracture. Thus, to maximize axial loading applied at the UIV, we limited the LIV to S-1 or pelvis. Cases of UIV at the proximal thoracic level were excluded because a fracture at this level is difficult to determine on follow-up 

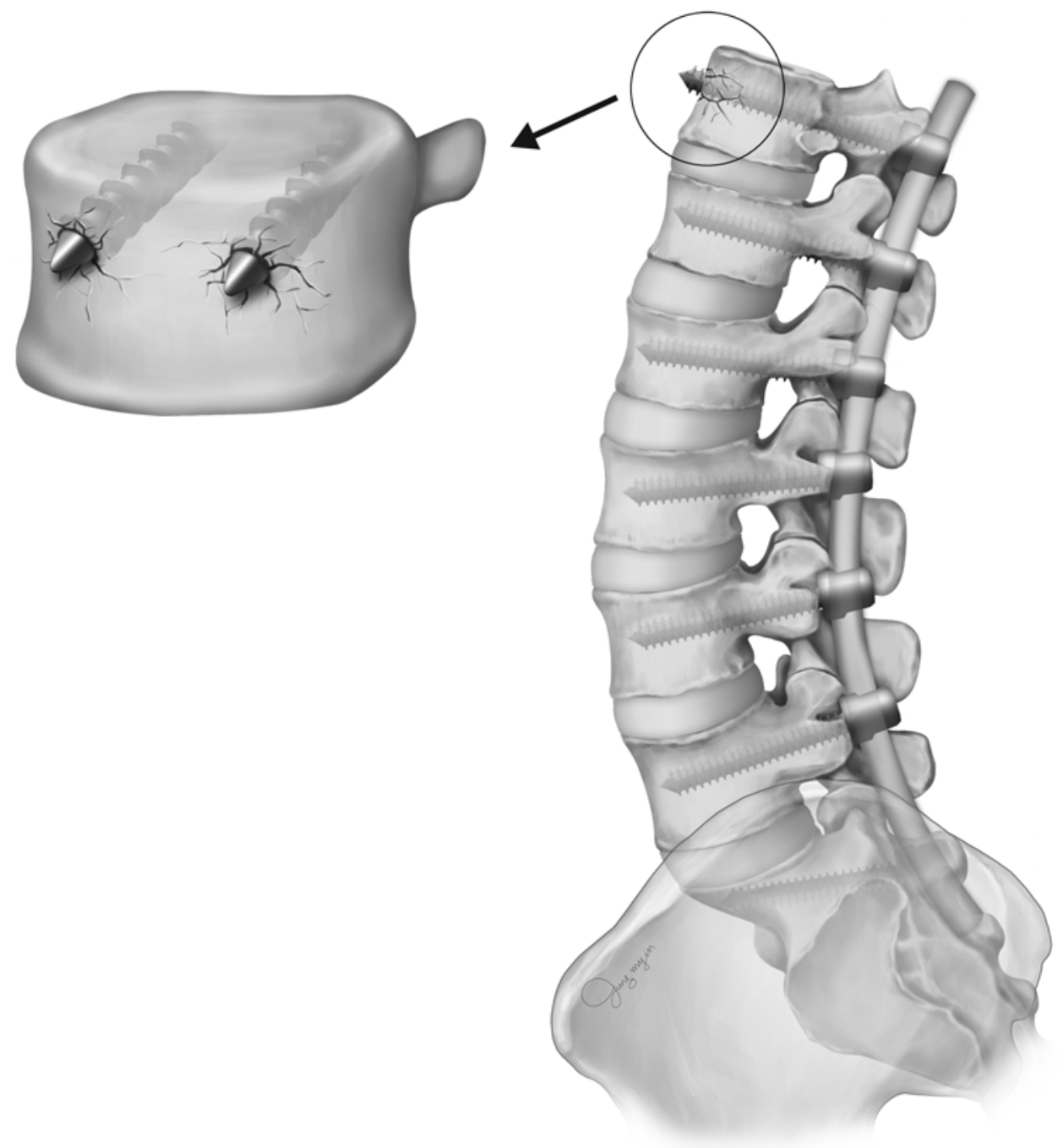

FIG. 3. A schematic drawing of UIV bicortical screw fixation. Breakage on the anterior cortical wall of the UIV by a bicortical screw caused a UIV fracture. Copyright Mi-Jin Jung. Published with permission.

radiographs, and the fracture incidence is lower. ${ }^{6}$ Groups $\mathrm{P}$ and $\mathrm{B}$ included 14 patients who had a UIV fracture; of those, 1 case had a UIV fracture at 158 days from the index surgery. In the remaining 13 patients, the mean time to UIV fracture was 27.15 days (range 5-70 days). This is a significant result considering that all patients wore a thoracolumbosacral orthosis brace for a minimum of 90 days after surgery.

Groups $\mathrm{U}$ and $\mathrm{B}$ showed a statistically significant difference in terms of the UIV fracture rate (OR 1.75; $p=0.005$ ), but differences between Groups U and B and Groups P and $B$ were not statistically significant. If the number of patients had been higher, we could have determined the relationships between Groups $\mathrm{U}$ and $\mathrm{P}$ and Groups $\mathrm{P}$ and $\mathrm{B}$. As hypothesized, this finding supports the idea that breakage on the anterior cortical wall of the UIV by a bicortical screw causes UIV fracture because it cannot bear the axial loading force exerted on the UIV (Fig. 3). Although there were no statistically significant differences, Groups P and $\mathrm{B}$ had a lower BMD, and the mean age was higher than that in Group U.
Our study was limited by the small number of patients. Also, the highest BMD was observed in Group U, which did not show fracture. Nevertheless, we think that our results related to bicortical screw fixation and early UIV fractures are significant and relevant. Additionally, conducting a biomechanical study could support our results.

\section{Conclusions}

Our clinical series of patients who underwent adult spinal deformity surgery showed that bicortical fixation at the UIV is a major risk factor for early UIV compression fracture. To reduce the incidence of APJF, unicortical screw fixation at the UIV is essential in adult spinal deformity surgery.

\section{References}

1. Annis P, Lawrence BD, Spiker WR, Zhang Y, Chen W, Daubs $\mathrm{MD}$, et al: Predictive factors for acute proximal junctional failure after adult deformity surgery with upper instrumented 
vertebrae in the thoracolumbar spine. Evid Based Spine Care J 5:160-162, 2014

2. Arlet V, Aebi M: Junctional spinal disorders in operated adult spinal deformities: present understanding and future perspectives. Eur Spine J 22 (Suppl 2):S276-S295, 2013

3. Cho SK, Shin JI, Kim YJ: Proximal junctional kyphosis following adult spinal deformity surgery. Eur Spine J 23:27262736, 2014

4. Dekutoski MB, Schendel MJ, Ogilvie JW, Olsewski JM, Wallace LJ, Lewis JL: Comparison of in vivo and in vitro adjacent segment motion after lumbar fusion. Spine (Phila Pa 1976) 19:1745-1751, 1994

5. Glattes RC, Bridwell KH, Lenke LG, Kim YJ, Rinella A, Edwards C II: Proximal junctional kyphosis in adult spinal deformity following long instrumented posterior spinal fusion: incidence, outcomes, and risk factor analysis. Spine (Phila Pa 1976) 30:1643-1649, 2005

6. Ha Y, Maruo K, Racine L, Schairer WW, Hu SS, Deviren V, et al: Proximal junctional kyphosis and clinical outcomes in adult spinal deformity surgery with fusion from the thoracic spine to the sacrum: a comparison of proximal and distal upper instrumented vertebrae. J Neurosurg Spine 19:360-369, 2013

7. Hostin R, McCarthy I, O’Brien M, Bess S, Line B, BoachieAdjei $\mathrm{O}$, et al: Incidence, mode, and location of acute proximal junctional failures after surgical treatment of adult spinal deformity. Spine (Phila Pa 1976) 38:1008-1015, 2013

8. Hyun SJ, Kim YJ, Rhim SC: Spinal pedicle subtraction osteotomy for fixed sagittal imbalance patients. World J Clin Cases 1:242-248, 2013

9. Hyun SJ, Rhim SC: Clinical outcomes and complications after pedicle subtraction osteotomy for fixed sagittal imbalance patients: a long-term follow-up data. J Korean Neurosurg Soc 47:95-101, 2010

10. Kim HJ, Boachie-Adjei O, Shaffrey CI, Schwab F, Lafage V, Bess S, et al: Upper thoracic versus lower thoracic upper instrumented vertebrae endpoints have similar outcomes and complications in adult scoliosis. Spine (Phila Pa 1976) 39:E795-E799, 2014

11. Kim YJ, Bridwell KH, Lenke LG, Kim J, Cho SK: Proximal junctional kyphosis in adolescent idiopathic scoliosis following segmental posterior spinal instrumentation and fusion: minimum 5-year follow-up. Spine (Phila Pa 1976) 30:20452050, 2005

12. Kim YJ, Bridwell KH, Lenke LG, Rhim S, Cheh G: An analysis of sagittal spinal alignment following long adult lumbar instrumentation and fusion to L5 or S1: can we predict ideal lumbar lordosis? Spine (Phila Pa 1976) 31:2343-2352, 2006

13. Kim YJ, Bridwell KH, Lenke LG, Rhim S, Cheh G: Sagittal thoracic decompensation following long adult lumbar spinal instrumentation and fusion to L5 or S1: causes, prevalence, and risk factor analysis. Spine (Phila Pa 1976) 31:23592366, 2006

14. Kim YJ, Bridwell KH, Lenke LG, Rhim S, Kim YW: Is the T9, T11, or L1 the more reliable proximal level after adult lumbar or lumbosacral instrumented fusion to L5 or S1? Spine (Phila Pa 1976) 32:2653-2661, 2007

15. Kim YJ, Lenke LG, Bridwell KH, Kim J, Cho SK, Cheh G, et al: Proximal junctional kyphosis in adolescent idiopathic scoliosis after 3 different types of posterior segmental spinal instrumentation and fusions: incidence and risk factor analysis of 410 cases. Spine (Phila Pa 1976) 32:2731-2738, 2007

16. Lee CK: Accelerated degeneration of the segment adjacent to a lumbar fusion. Spine (Phila Pa 1976) 13:375-377, 1988
17. Lewis SJ, Abbas H, Chua S, Bacon S, Bronstein Y, Goldstein S, et al: Upper instrumented vertebral fractures in long lumbar fusions: what are the associated risk factors? Spine (Phila Pa 1976) 37:1407-1414, 2012

18. McLain RF: The biomechanics of long versus short fixation for thoracolumbar spine fractures. Spine (Phila Pa 1976) 31 (11 Suppl):S70-S79, S104, 2006

19. Penta M, Sandhu A, Fraser RD: Magnetic resonance imaging assessment of disc degeneration 10 years after anterior lumbar interbody fusion. Spine (Phila Pa 1976) 20:743-747, 1995

20. Phillips FM, Reuben J, Wetzel FT: Intervertebral disc degeneration adjacent to a lumbar fusion. An experimental rabbit model. J Bone Joint Surg Br 84:289-294, 2002

21. Rahm MD, Hall BB: Adjacent-segment degeneration after lumbar fusion with instrumentation: a retrospective study. $\mathbf{J}$ Spinal Disord 9:392-400, 1996

22. Schlegel JD, Smith JA, Schleusener RL: Lumbar motion segment pathology adjacent to thoracolumbar, lumbar, and lumbosacral fusions. Spine (Phila Pa 1976) 21:970-981, 1996

23. Smith MW, Annis P, Lawrence BD, Daubs MD, Brodke DS: Acute proximal junctional failure in patients with preoperative sagittal imbalance. Spine J 15:2142-2148, 2015

24. Smith MW, Annis P, Lawrence BD, Daubs MD, Brodke DS: Early proximal junctional failure in patients with preoperative sagittal imbalance. Evid Based Spine Care J 4:163-164, 2013

25. Watanabe K, Lenke LG, Bridwell KH, Kim YJ, Koester L, Hensley M: Proximal junctional vertebral fracture in adults after spinal deformity surgery using pedicle screw constructs: analysis of morphological features. Spine (Phila Pa 1976) 35:138-145, 2010

26. Weinhoffer SL, Guyer RD, Herbert M, Griffith SL: Intradiscal pressure measurements above an instrumented fusion. A cadaveric study. Spine (Phila Pa 1976) 20:526-531, 1995

27. Zhu Y, Wang K, Wang B, Wang H, Jin Z, Zhu Z, et al: Selection of proximal fusion level for degenerative scoliosis and the entailing proximal-related late complications. Int J Clin Exp Med 8:5731-5738, 2015

\section{Disclosures}

The authors report no conflict of interest concerning the materials or methods used in this study or the findings specified in this paper.

\section{Author Contributions}

Conception and design: Park. Acquisition of data: Park. Analysis and interpretation of data: Park. Drafting the article: Park. Critically revising the article: Park, Choi, Kim, Jahng. Reviewed submitted version of manuscript: all authors. Approved the final version of the manuscript on behalf of all authors: Hyun. Statistical analysis: Park. Administrative/technical/material support: Park, Choi, Kim, Jahng. Study supervision: Hyun, Kim, Jahng.

\section{Correspondence}

Seung-Jae Hyun, Department of Neurosurgery, Spine Center, Seoul National University Bundang Hospital, Seoul National University College of Medicine, 82, Gumi-ro 173 beon-gil, Bundang, Seongnam, Gyeonggi 13620, Korea. email: hyunsj@snu.ac.kr. 